\title{
Polymorphisms in bone morphogenetic protein 3 and the risk of papillary thyroid cancer
}

\author{
YOUNG OCK KIM ${ }^{1}$, IL KI HONG ${ }^{2}$, YOUNG GYU EUN ${ }^{2}$, SEONG-SU NAH ${ }^{3}$, SOOJEONG LEE ${ }^{4,5}$, \\ SU-HAK HEO ${ }^{5,6}$, HYUNG-KEE KIM ${ }^{7}$, HO-YEON SONG ${ }^{4}$ and HAK-JAE KIM ${ }^{4,5}$ \\ ${ }^{1}$ Development of Ginseng and Medical Plants Research Institute, Rural Administration, Eumseong; \\ ${ }^{2}$ Department of Otolaryngology-Head and Neck Surgery, School of Medicine, Kyung Hee University, Seoul; \\ ${ }^{3}$ Division of Rheumatology, Department of Internal Medicine, College of Medicine, Soonchunhyang University; \\ ${ }^{4}$ Department of Microbiology; ${ }^{5}$ Soonchunhyang Medical Research Institute, \\ College of Medicine, Soonchunhyang University; ${ }^{6}$ Executive Office, \\ The National Project for Personalized Genomic Medicine, Ministry of Health and Welfare; \\ ${ }^{7}$ Clinical Pharmacology, College of Medicine, Soonchunhyang University, Cheonan, Republic of Korea
}

Received June 6, 2012; Accepted August 29, 2012

DOI: 10.3892/ol.2012.962

\begin{abstract}
Bone morphogenetic proteins (BMPs) are members of the transforming growth factor beta (TGF $\beta$ ) superfamily with well-described functions in bone formation. Although disrupted BMP signaling in tumor development has been investigated, a genetic association for BMP3 in papillary thyroid cancer (PTC) has remained largely unexplored. In this study, we investigated whether BMP3 single nucleotide polymorphisms (SNPs) are associated with the development of PTC and its clinicopathological features. A total of 103 PTC patients and 324 control subjects were enrolled. One promoter SNP (rs13138132; -1919C/A) and one missense mutation (rs3733549; Arg192Gln) in BMP3 were genotyped by direct sequencing. SNPStats, SNPAnalyzer, Helixtree and Haploview version 4.2 were used to evaluate the genetic data. Multiple logistic regression models were used to calculate odds ratios (ORs), 95\% confidence intervals (CIs) and P-values. The missense SNP (rs3733549) was weakly associated with the development of PTC in a codominant model (AA vs. GG; $\mathrm{P}=0.017$ ) and a recessive model (AA vs. $\mathrm{GG} / \mathrm{GA} ; \mathrm{P}=0.023$ ). Additionally, in an analysis according to clinicopathological features, rs13138132 was significantly associated with extrathyroidal invasion in a codominant model (CA vs. CC; $\mathrm{P}=0.006)$ and a dominant model (CA/AA vs. $\mathrm{CC} ; \mathrm{P}=0.0023$ ). We also identified that the frequency of the A allele in the promoter SNP (rs13138132) was increased in PTC patients
\end{abstract}

Correspondence to: Dr Hak-Jae Kim, Department of Microbiology, College of Medicine, Soonchunhyang University, 366-1, \#319, Cheonan, Chungnam 330-090, Republic of Korea E-mail: hak3962@sch.ac.kr

Key words: papillary thyroid cancer, bone morphogenic protein 3, polymorphism, extrathyroidal invasion with extrathyroidal invasion $(\mathrm{P}=0.004)$. Our data suggest that rs3733549 in BMP3 is associated with the development of PTC and that the A allele of rs13138932 in BMP3 is a risk factor for extrathyroidal invasion.

\section{Introduction}

Thyroid cancer is the most common type of endocrine malignancy, accounting for approximately $1 \%$ of all cases of cancer. It is the most rapidly increasing cancer among females and the second most rapidly increasing cancer among males. Histologically, thyroid cancer is classified as papillary thyroid cancer (PTC), follicular thyroid cancer, medullary thyroid cancer or undifferentiated or anaplastic thyroid cancer. Of these, PTC is the most common type, and it accounts for $85-90 \%$ of all thyroid malignancies $(1,2)$. Although the etiology of PTC is unclear, environmental factors, including radiation, diet, smoking and hormones, have been identified to affect the pathogenesis of thyroid cancer $(3,4)$. Genetic predisposition has also been implicated as a risk factor for thyroid cancer development $(5,6)$.

Bone morphogenic proteins (BMPs) have been demonstrated to play an important role during development (particularly during bone formation) and in the regulation of various cellular processes, including cell proliferation, apoptosis and differentiation (7). Evidence suggests that BMPs are important in tumorigenesis (8-10). BMPs are members of the transforming growth factor beta (TGF $\beta$ ) family; thus, BMPs utilize a similar signaling cascade to that of TGF $\beta$. BMPs have been identified to utilize the SMAD signaling pathway for their growth suppressive effects, and also to affect PTEN and p21 (WAF1) expression via RAS-ERK signaling in cancer (10-12). Additionally, previous studies have revealed that genetic variations in BMP genes are associated with a number of types of cancer (13-15). Genome-wide association studies have demonstrated associations between polymorphisms in BMP2 (13) and BMP4 $(13,14)$ and colorectal cancer. Park et al $(15)$ also 
suggested that a frame-shift mutation in BMP receptor type II (BMPR2) contributes to the pathogenesis of gastric and colorectal cancers by inactivating BMPR2-mediated BMP signaling.

BMP3 plays an important role in embryonic development by inducing and patterning early skeletal formation. In vitro studies have also suggested a role for BMP3 as a negative growth regulator in bone marrow progenitor cells through the inhibition of DNA synthesis and proliferation (16). Additionally, recent studies have revealed that BMP3 contributes to tumor development and progression (17-19). However, to the best of our knowledge, no study of a possible genetic association between polymorphisms in BMP3 and cancer has been conducted. In this study, we investigated the association between single nucleotide polymorphisms (SNPs) in BMP3 and PTC, as well as the clinicopathological features of PTC, including cancer size, tumor number, cancer location, extrathyroidal invasion and metastasis. To the best of our knowledge, this is the first study to investigate the association between BMP3 SNPs and cancer, with particular interest in PTC.

\section{Materials and methods}

Patients and control subjects. PTC patients were enrolled at Kyung Hee University Medical Center, Seoul, Korea, between October 2007 and December 2010. Control subjects were selected from healthy individuals examined under a general health check-up program to ensure that there was no clinical evidence of cancer, thyroid disease or any other severe conditions. PTC and cervical region lymph node metastasis were confirmed by pathological examination. Specimens confirmed as a benign tumor, follicular variant, diffuse sclerosing variant or tall cell variant were excluded. The mean age of the patients was $54.7 \pm 12.3$ years. The patient group $(n=105)$ was comprised of 29 males and 76 females, while the control group consisted of 324 healthy adults $(53.8 \pm 6.0$ years), including 132 males and 192 females. This study was approved by the ethics review board of the Medical Research Institute, Kyung Hee University Medical Center (KMC IRB 1010-05). Written informed consent was obtained from each subject prior to study entry.

Patient subgroups. To determine the nature of the correlation between BMP3 polymorphisms and the clinicopathological characteristics of PTC, the patients were divided into subgroups according to the size of the tumor $(<1 \mathrm{vs} . \geq 1 \mathrm{~cm})$, number of tumors (unifocal vs. multifocal), location of the cancer (one lobe vs. both lobes), extrathyroidal invasion (presence vs. absence), cervical lymph node metastasis (presence vs. absence) and angiolymphatic invasion (presence vs. absence). The demographic characteristics of the PTC patients are summarized in Table I; small differences in subgroup numbers were caused by the loss of certain clinical data.

SNP selection and genotyping. We searched for promoter and coding SNPs in BMP3 in the SNP database of the National Center for Biotechnology Information (http://www.ncbi.nlm. nih.gov/SNP; BUILD 135). Those SNPs without genotype
Table I. Clinical characteristics of the study population.

\begin{tabular}{|c|c|c|}
\hline Characteristics & PTC (n) & Control \\
\hline Age, years $($ mean $\pm \mathrm{SD})$ & $54.7 \pm 12.3$ & $56.3 \pm 11.9$ \\
\hline \multicolumn{3}{|l|}{ Gender } \\
\hline Male & 29 & 132 \\
\hline Female & 76 & 192 \\
\hline \multicolumn{3}{|l|}{ Tumor size, $\mathrm{cm}$} \\
\hline$<1$ & 53 & \\
\hline$\geq 1$ & 50 & \\
\hline \multicolumn{3}{|l|}{ Number of tumors } \\
\hline Unifocal & 66 & \\
\hline Multifocal & 35 & \\
\hline \multicolumn{3}{|l|}{ Cancer location } \\
\hline One lobe & 65 & \\
\hline Both lobes & 36 & \\
\hline \multicolumn{3}{|l|}{ Extrathyroidal invasion } \\
\hline Absent & 49 & \\
\hline Present & 53 & \\
\hline \multicolumn{3}{|c|}{ Cervical lymph node metastasis } \\
\hline Absent & 67 & \\
\hline Present & 30 & \\
\hline \multicolumn{3}{|l|}{ Angiolymphatic invasion } \\
\hline Absent & 94 & \\
\hline Present & 6 & \\
\hline
\end{tabular}

PTC patients with inappropriate clinical data were excluded. PTC, papillary thyroid cancer; SD, standard deviation.

frequency data and with a heterozygosity $\leq 0.1$ or a minor allele frequency $\leq 0.1$ were excluded. Ultimately, two SNPs (rs13138132, -1919C/A; rs3733549, Arg192Gln) were selected. Blood samples for DNA extraction were collected from each subject in ethylene diamine tetracetic acid (EDTA) tubes and stored at $-80^{\circ} \mathrm{C}$. Genomic DNA was extracted using a QIAamp ${ }^{\circledR}$ DNA mini kit (Qiagen, Hilden, Germany). SNP genotyping was conducted by direct sequencing. Polymerase chain reactions (PCRs) were conducted using primers specific for the BMP3 SNPs that were selected for analysis (rs13138132: sense, 5'-GTGTGACTCCAGGAGCCTATCT-3'; antisense, 5'-TGA GCTAACATTTTTCTC CACAC-3'; product size, 376 bp; and rs3733549: sense, 5'-AGTTGTCCAGTGTCTGGAGGAT-3'; antisense, 5'-TCCCTGTAAGCTTGATACCACA-3'; product size, $351 \mathrm{bp})$. The products were sequenced using an ABI PRISM 3730XL analyzer (PE Applied Biosystems, Foster City, CA, USA). The sequenced data were analyzed using SeqMan II software (DNASTAR, Madison, WI, USA).

Statistical analysis. SNPStats (http://bioinfo.iconcologia.net/ SNPstats) and SPSS 18.0 (SPSS Inc., Chicago, IL, USA) were used to analyze the genetic data and the Hardy-Weinberg equilibrium (HWE). Associations between the SNP genotypes and PTC, and associations between the SNP genotypes and PTC subgroups, were estimated by computing the odds ratios (ORs) 
Table II. Comparison of genotype and allele frequencies of BMP3 polymorphisms between control and PTC patients.

\begin{tabular}{|c|c|c|c|c|c|c|c|c|}
\hline \multirow[b]{2}{*}{ SNP } & \multirow[b]{2}{*}{ Model/allele } & \multirow[b]{2}{*}{ Genotype } & \multicolumn{2}{|c|}{ Control } & \multicolumn{2}{|c|}{ PTC } & \multirow[b]{2}{*}{ OR $(95 \%$ CI $)$} & \multirow[b]{2}{*}{ P-value } \\
\hline & & & $\mathrm{n}$ & $\%$ & $\mathrm{n}$ & $\%$ & & \\
\hline \multirow{9}{*}{$\begin{array}{l}\text { rs13138132 } \\
(-1919 \mathrm{C} / \mathrm{A})\end{array}$} & \multirow[t]{3}{*}{ Codominant } & $\mathrm{CC}$ & 228 & 70.4 & 68 & 64.8 & Ref. & \\
\hline & & CA & 91 & 28.1 & 35 & 33.3 & $1.31(0.81-2.13)$ & 0.29 \\
\hline & & AA & 5 & 1.5 & 2 & 1.9 & $1.38(0.26-7.46)$ & 0.73 \\
\hline & \multirow[t]{2}{*}{ Dominant } & $\mathrm{CC}$ & 228 & 70.4 & 68 & 64.8 & Ref. & \\
\hline & & CA/AA & 96 & 29.6 & 37 & 35.2 & $1.32(0.82-2.12)$ & 0.26 \\
\hline & \multirow[t]{2}{*}{ Recessive } & $\mathrm{CC} / \mathrm{CA}$ & 319 & 98.5 & 103 & 98.1 & Ref. & \\
\hline & & AA & 5 & 1.5 & 2 & 1.9 & $1.27(0.24-6.79)$ & 0.78 \\
\hline & \multirow[t]{2}{*}{ Allele } & $\mathrm{C}$ & 547 & 84.4 & 171 & 81.4 & Ref. & \\
\hline & & A & 101 & 15.6 & 39 & 18.6 & $1.24(0.82-1.86)$ & 0.31 \\
\hline \multirow{9}{*}{$\begin{array}{l}\text { rs3733549 } \\
\text { (Arg192Gln) }\end{array}$} & \multirow[t]{3}{*}{ Codominant } & GG & 217 & 67.0 & 64 & 62.1 & Ref. & \\
\hline & & GA & 101 & 31.2 & 32 & 31.1 & $1.08(0.66-1.78)$ & 0.77 \\
\hline & & AA & 6 & 1.8 & 7 & 6.8 & $3.98(1.24-12.73)$ & $0.017^{\mathrm{a}}$ \\
\hline & \multirow[t]{2}{*}{ Dominant } & GG & 217 & 67.0 & 64 & 62.1 & Ref. & \\
\hline & & GA/AA & 107 & 33.0 & 39 & 37.9 & $1.24(0.78-1.99)$ & 0.36 \\
\hline & \multirow[t]{2}{*}{ Recessive } & GG/GA & 318 & 98.2 & 96 & 93.2 & Ref. & \\
\hline & & AA & 6 & 1.8 & 7 & 6.8 & $3.88(1.23-12.25)$ & $0.023^{\mathrm{a}}$ \\
\hline & \multirow{2}{*}{ Allele } & $\mathrm{G}$ & 535 & 82.6 & 160 & 77.7 & Ref. & \\
\hline & & A & 113 & 17.4 & 46 & 22.3 & $1.36(0.93-2.00)$ & 0.12 \\
\hline
\end{tabular}

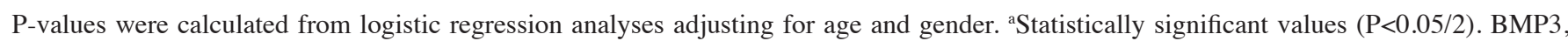
bone morphogenic protein 3; PTC, papillary thyroid cancer. SNP, single nucleotide polymorphism; OR, odds ratio; CI, confidence interval.

and $95 \%$ CIs with logistic regression analyses, controlling for age and gender as covariables. In the logistic regression analysis for each SNP, models assuming codominant inheritance, dominant inheritance or recessive inheritance were used. The $\chi^{2}$ test was used to compare allele frequencies between groups. To avoid chance findings due to multiple testing, the Bonferroni correction was applied by lowering the significance levels to $\mathrm{P}=0.025(\mathrm{P}=0.05 / 2)$ for the two SNPs.

\section{Results}

Genetic associations between BMP3 and PTC. The genotypic distributions of the SNPs examined in this study were in HWE ( $\mathrm{P}>0.05$; data not shown). Genetic associations between BMP3 and PTC were investigated. Multiple logistic regression analyses were conducted for the promoter SNP rs13138132 (codominant, CA vs. CC and AA vs. CC; dominant, $\mathrm{CA} / \mathrm{AA}$ vs. $\mathrm{CC}$; recessive, $\mathrm{AA}$ vs. $\mathrm{CC} / \mathrm{CA}$ ) and the missense SNP rs3733549 (codominant, GA vs. GG and AA vs. GG; dominant, GA/AA vs. GG; recessive, AA vs. GG/GA).

As shown in Table II, the genotype frequencies of rs3733549 were significantly different between the PTC patients and control subjects in the codominant (AA vs. GG) and recessive models (AA vs. GG/GA). In the codominant model, the frequencies of the GG and AA genotypes were 67.0 and $1.8 \%$ in the control group, and 62.1 and $6.8 \%$ in the PTC group, respectively. The AA genotype was associated with an increased risk of PTC $(\mathrm{P}=0.017, \mathrm{OR}=3.98$ and $95 \% \mathrm{CI}=1.24-12.73)$. In the recessive model, the frequencies of the genotypes containing the $\mathrm{G}$ allele (GG/GA) and the genotypes not containing the $\mathrm{G}$ allele (AA) were 98.2 and $1.8 \%$ in the control group and 93.2 and $6.8 \%$ in the PTC group, respectively. The frequency of the genotype not containing the $\mathrm{G}$ allele was significantly increased in the PTC patients compared with the control subjects $(\mathrm{P}=0.023, \mathrm{OR}=3.88,95 \% \mathrm{CI}=1.23-12.25)$. $\mathrm{rs} 13138132$ was not significantly associated with PTC.

Genetic correlation between the SNPs and PTC patient subgroups. When we assessed the genetic correlation between the SNPs and PTC patient subgroups, the BMP3 SNPrs13138132 was significantly associated with PTC with extrathyroidal invasion in the codominant (CA vs. $\mathrm{CC} ; \mathrm{P}=0.006, \mathrm{OR}=3.52$ and $95 \% \mathrm{CI}=1.44-8.62)$ and dominant models (CA/AA vs. $\mathrm{CC}$; $\mathrm{P}=0.0023, \mathrm{OR}=3.79$ and $95 \% \mathrm{CI}=1.56-9.21$; Table III). The frequencies of genotypes containing the A allele (CA/AA genotypes) were increased in PTC patients with extrathyroidal invasion (49.1\%) compared with PTC patients without extrathyroidal invasion (20.4\%). Allele frequency analysis revealed that rs13138132 was associated with extrathyroidal invasion $(\mathrm{P}=0.004, \mathrm{OR}=3.16,95 \% \mathrm{CI}=1.44-6.92)$, and that the frequency of the A allele was increased in PTC patients with extrathyroidal invasion (10.2 and $26.4 \%$ in PTC patients without and with extrathyroidal invasion, respectively). rs3733549 did not demonstrate any association with cancer size, tumor number, cancer location, extrathyroidal invasion, angiolymphatic invasion or cervical lymph node metastasis. 
Table III. Comparison of genotype and allele frequencies of BMP3 polymorphisms bwtween PTC patients with and without extrathyroidal invasion.

\begin{tabular}{|c|c|c|c|c|c|c|c|c|}
\hline \multirow[b]{3}{*}{ SNP } & \multirow[b]{3}{*}{ Model/allele } & \multirow[b]{3}{*}{ Genotype } & \multicolumn{4}{|c|}{ Extrathyroidal invasion } & \multirow[b]{3}{*}{ OR $(95 \% \mathrm{CI})$} & \multirow[b]{3}{*}{ P-value } \\
\hline & & & \multicolumn{2}{|c|}{ - } & \multicolumn{2}{|c|}{+} & & \\
\hline & & & $\mathrm{n}$ & $\%$ & $\mathrm{n}$ & $\%$ & & \\
\hline \multirow{9}{*}{$\begin{array}{l}\text { rs13138132 } \\
(-1919 \mathrm{C} / \mathrm{A})\end{array}$} & \multirow[t]{3}{*}{ Codominant } & $\mathrm{CC}$ & 39 & 79.6 & 27 & 50.9 & Ref. & \\
\hline & & $\mathrm{CA}$ & 10 & 20.4 & 24 & 45.3 & $3.52(1.44-8.62)$ & $0.006^{\mathrm{a}}$ \\
\hline & & AA & 0 & 0 & 2 & 3.8 & NA & \\
\hline & \multirow[t]{2}{*}{ Dominant } & $\mathrm{CC}$ & 39 & 79.6 & 27 & 50.9 & Ref. & \\
\hline & & CA/AA & 10 & 20.4 & 26 & 49.1 & $3.79(1.56-9.21)$ & $0.0023^{\mathrm{a}}$ \\
\hline & \multirow[t]{2}{*}{ Recessive } & $\mathrm{CC} / \mathrm{CA}$ & 49 & 100 & 51 & 96.2 & Ref. & \\
\hline & & $\mathrm{AA}$ & 0 & 0 & 2 & 3.8 & NA & \\
\hline & \multirow[t]{2}{*}{ Allele } & $\mathrm{C}$ & 88 & 89.8 & 78 & 73.6 & Ref. & \\
\hline & & A & 10 & 10.2 & 28 & 26.4 & $3.16(1.44-6.92)$ & $0.004^{\mathrm{a}}$ \\
\hline \multirow{9}{*}{$\begin{array}{l}\text { rs3733549 } \\
\text { (Arg192Gln) }\end{array}$} & \multirow[t]{3}{*}{ Codominant } & GG & 28 & 59.6 & 34 & 64.2 & Ref. & \\
\hline & & GA & 14 & 29.8 & 17 & 32 & $0.99(0.41-2.39)$ & 1 \\
\hline & & $\mathrm{AA}$ & 5 & 10.6 & 2 & 3.8 & $0.33(0.06-1.89)$ & 0.20 \\
\hline & \multirow[t]{2}{*}{ Dominant } & GG & 28 & 59.6 & 34 & 64.2 & Ref. & \\
\hline & & GA/AA & 19 & 40.4 & 19 & 35.8 & $0.82(0.36-1.88)$ & 0.65 \\
\hline & \multirow[t]{2}{*}{ Recessive } & GG/GA & 42 & 89.4 & 51 & 96.2 & Ref. & \\
\hline & & AA & 5 & 10.6 & 2 & 3.8 & $0.33(0.06-1.84)$ & 0.18 \\
\hline & \multirow[t]{2}{*}{ Allele } & G & 70 & 74.5 & 85 & 80.2 & Ref. & \\
\hline & & A & 24 & 25.5 & 21 & 19.8 & $0.72(0.37-1.40)$ & 0.34 \\
\hline
\end{tabular}

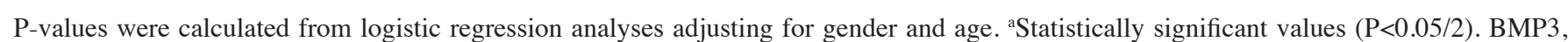
bone morphogenic protein 3; PTC, papillary thyroid cancer. SNP, single nucleotide polymorphism; OR, odds ratio; CI, confidence interval; NA, not applicable.

\section{Discussion}

The results of the present study indicate an association between the BMP3 gene and PTC. The rs3733549 SNP of BMP3 was associated with PTC, and the AA genotype contributed to an increased risk of PTC. Additionally, the rs13138132 SNP was associated with extrathyroidal invasion in PTC patients. In particular, we identified that the frequency of the A allele was increased in PTC patients with extrathyroidal invasion.

Although the role of BMP3 in the pathogenesis of cancer is unknown, several studies have demonstrated that BMP3 participates in the development of various types of cancer (17-21). Loh et al (17) reported that in colon cancer cell lines with methylation-dependent BMP3 downregulation, cell colony growth suppression was observed following the reintroduction of BMP3 coding sequences. Methylation of the BMP3 promoter has also been described in subtypes of stomach (18), lung (20), pancreatic (19) and breast cancers (21) with downregulated BMP3 expression. Considering the results of these previous studies, we speculated that BMP3 is also involved in the development of PTC. In our study, we revealed a weak association between rs3733549 and PTC.

Additionally, the SNP rs13138132 in BMP3 was associated with extrathyroidal invasion in PTC patients, and the frequency of the minor A allele was increased in PTC patients with extrathyroidal invasion. Extrathyroidal invasion is one of the most prominent prognostic risk factors for a poor clinical outcome in patients with PTC (22). As mentioned, BMP3 may negatively regulate cellular processes including migration, proliferation and differentiation (16-19). In addition, BMP3 gene expression has been identified to be downregulated with hypermethylation of the BMP3 promoter region in various types of cancer (17-19). The SNP rs13138132 is located in a predicted promoter enhancing region (http://asia.ensembl.org/index.html); thus, we speculated that rs13138132 affects promoter activity and methylation of the BMP3 gene, and that rs13138132 eventually contributes to extrathyroidal invasion in PTC. Additional studies are required to determine how BMP3 polymorphisms affect the pathogenesis of cancers, including PTC.

In conclusion, we obtained significant evidence to support an association between BMP3 and PTC. In particular, the AA genotype of rs3733549 was associated with the development of PTC, and the A alleles of rs13138132 were implicated as a risk factor for extrathyroidal invasion in PTC. Thus, our results suggest that BMP3 plays a role in the pathogenesis of PTC. Due to the relatively small number of subjects, our results should be validated by additional studies using larger sample sizes. 


\section{References}

1. Hundahl SA, Fleming ID, Fremgen AM and Menck HR: A National Cancer Data Base report on 53,856 cases of thyroid carcinoma treated in the U.S., 1985-1995 [see comments]. Cancer 83: 2638-2648, 1998.

2. Dohan O, Baloch Z, Banrevi Z, Livolsi V and Carrasco N: Rapid communication: predominant intracellular overexpression of the $\mathrm{Na}(+) / \mathrm{I}(-)$ symporter (NIS) in a large sampling of thyroid cancer cases. J Clin Endocrinol Metab 86: 2697-2700, 2001.

3. Kondo T, Ezzat S and Asa SL: Pathogenetic mechanisms in thyroid follicular-cell neoplasia. Nat Rev Cancer 6: 292-306, 2006.

4. Grubbs EG, Rich TA, Li G, Sturgis EM, Younes MN, et al: Recent advances in thyroid cancer. Curr Probl Surg 45: 156-250, 2008.

5. Malchoff CD and Malchoff DM: Familial nonmedullary thyroid carcinoma. Cancer Control 13: 106-110, 2006.

6. Sturgis EM and Li G: Molecular epidemiology of papillary thyroid cancer: in search of common genetic associations. Thyroid 19: 1031-1034, 2009.

7. Ducy P and Karsenty G: The family of bone morphogenetic proteins. Kidney Int 57: 2207-2214, 2000.

8. Nosho K, Yamamoto H, Adachi Y, Endo T, Hinoda Y, et al: Gene expression profiling of colorectal adenomas and early invasive carcinomas by cDNA array analysis. Br J Cancer 92: 1193-1200, 2005

9. Koehler A, Bataille F, Schmid C, Ruemmele P, Waldeck A, et al: Gene expression profiling of colorectal cancer and metastases divides tumours according to their clinicopathological stage. J Pathol 204: 65-74, 2004.

10. Kraunz KS, Nelson HH, Liu M, Wiencke JK and Kelsey KT: Interaction between the bone morphogenetic proteins and Ras/MAP-kinase signalling pathways in lung cancer. Br J Cancer 93: 949-952, 2005.

11. Beck SE and Carethers JM: BMP suppresses PTEN expression via RAS/ERK signaling. Cancer Biol Ther 6: 1313-1317, 2007.

12. Beck SE, Jung BH, Del Rosario E, Gomez J and Carethers JM: BMP-induced growth suppression in colon cancer cells is mediated by 21 WAF1 stabilization and modulated by RAS/ERK. Cell Signal 19: 1465-1472, 2007.
13. Tomlinson IP, Carvajal-Carmona LG, Dobbins SE, Tenesa A, Jones AM, et al: Multiple common susceptibility variants near BMP pathway loci GREM1, BMP4, and BMP2 explain part of the missing heritability of colorectal cancer. PLoS Genet 7: e1002105, 2011.

14. Fernandez-Rozadilla C, de Castro L, Clofent J, Brea-Fernandez A, Bessa X, et al: Single nucleotide polymorphisms in the Wnt and BMP pathways and colorectal cancer risk in a Spanish cohort. PLoS One 5: e12673, 2010.

15. Park SW, Hur SY, Yoo NJ and Lee SH: Somatic frameshift mutations of bone morphogenic protein receptor 2 gene in gastric and colorectal cancers with microsatellite instability. APMIS 118: 824-829, 2010.

16. Amedee J, Bareille R, Rouais F, Cunningham N, Reddi H, et al: Osteogenin (bone morphogenic protein 3 ) inhibits proliferation and stimulates differentiation of osteoprogenitors in human bone marrow. Differentiation 58: 157-164, 1994.

17. Loh K, Chia JA, Greco S, Cozzi SJ, Buttenshaw RL, et al: Bone morphogenic protein 3 inactivation is an early and frequent event in colorectal cancer development. Genes Chromosomes Cancer 47: 449-460, 2008.

18. Chen XR, Wang JW, Li X, Zhang H and Ye ZY: Role of BMP3 in progression of gastric carcinoma in Chinese people. World $\mathrm{J}$ Gastroenterol 16: 1409-1413, 2010

19. Kisiel JB, Yab TC, Taylor WR, Chari ST, Petersen GM, et al: Stool DNA testing for the detection of pancreatic cancer: assessment of methylation marker candidates. Cancer 118: 2623-2631, 2012

20. Dai Z, Popkie AP, Zhu WG, Timmers CD, Raval A, et al: Bone morphogenetic protein $3 \mathrm{~B}$ silencing in non-small-cell lung cancer. Oncogene 23: 3521-3529, 2004.

21. Ronneberg JA, Fleischer T, Solvang HK, Nordgard SH, Edvardsen $\mathrm{H}$, et al: Methylation profiling with a panel of cancer related genes: association with estrogen receptor, TP53 mutation status and expression subtypes in sporadic breast cancer. Mol Oncol 5: 61-76, 2011.

22. Hotomi M, Sugitani I, Toda K, Kawabata K and Fujimoto Y: A novel definition of extrathyroidal invasion for patients with papillary thyroid carcinoma for predicting prognosis. World $\mathbf{J}$ Surg 36: 1231-1240, 2012. 